\title{
Imaging the interaction of roots and phosphate fertiliser granules using 4D X-ray tomography
}

\author{
Sharif Ahmed • Trudy Naugler Klassen • \\ Samuel Keyes • Michael Daly • David L. Jones • \\ Mark Mavrogordato • Ian Sinclair • Tiina Roose
}

Received: 16 December 2014 / Accepted: 19 February 2015

(C) Springer International Publishing Switzerland 2015

\begin{abstract}
Aims Plant root system architecture adapts to the prevailing soil environment and the distribution of nutrients. Many species respond to localised regions of high nutrient supply, found in the vicinity of fertiliser granules, by elevating branching density in these areas. However, observation of these adaptations is frequently limited to plants cultured in idealised materials (e.g., hydrogels) which have a structure-less, homogenous matrix, which are spatially limited and in the case of rhizotron observation provide only $2 \mathrm{D}$ data that are not fully quantitative. Methods In this study, in vivo, time resolved, microfocus X-ray $\mathrm{CT}$ imaging $(\mu \mathrm{CT})$ in $3 \mathrm{D}$ was used to visualise, quantify and assess root/fertiliser interactions of wheat plants in an agricultural soil during the entire plant life cycle. Two contrasting fertilisers [Triple superphosphate (TSP) and struvite (Crystal Green $\left.\left.{ }^{\circledR}\right)\right]$ were
\end{abstract}

Responsible Editor: Philippe Hinsinger.

S. Ahmed $\cdot$ S. Keyes $\cdot$ T. Roose

Crop Systems Engineering Group, Institute for Life Sciences, University of Southampton, University Road,

Southampton SO17 1BJ, UK

T. N. Klassen

Ostara Nutrient Recovery Technologies, Vancouver, BC V6E

2R1, Canada

M. Daly

The Agrology House, 7 Roselea Avenue, Welton, Lincoln LN2 3RT, UK

D. L. Jones

School of Environment, Natural Resources and Geography,

Bangor University, Bangor, Gwynedd LL57 2UW, UK applied according to 3 different treatments, each providing an equivalent of $80 \mathrm{~kg} \mathrm{P}_{2} \mathrm{O}_{5}$ ha $^{-1}$ (struvite only, TSP only and a 50:50 mixture) to each plant. $\mu \mathrm{CT}$ scans (60 $\mu \mathrm{m}$ spatial resolution) of the plant roots were obtained over 14 weeks.

Results This is the first time that in situ root/soil/ fertiliser interactions have been visualised in 3D from plant germination through to maturity. Results show that lateral roots tend to pass within a few millimetres of the phosphorus $(\mathrm{P})$ source. At this length scale, roots are able to access the $\mathrm{P}$ diffusing from the granule.

Conclusions Quantitative analysis of root/fertiliser interactions has shown that rooting density correlates with granule volume-loss for a slow release, struvite fertiliser.

Keywords Rhizosphere Phosphorus · Wastewater Fertilizer placement $\cdot$ Dissolution $\cdot$ Nutrient cycling

\section{S. Ahmed $\cdot$ S. Keyes $\cdot$ T. Roose \\ Bioengineering Sciences Research Group, Faculty of \\ Engineering and the Environment, University of Southampton, University Road, Southampton SO17 1BJ, UK}




\section{Introduction}

The combination of an increasing human population and progressive loss of soil quality in many countries around the world represents a major threat to global food security (Godfray et al. 2010). In the second half of the 20th Century, the Green Revolution averted a similar crisis through the targeted breeding of above-ground traits combined with intensive fertilisation (Khush 2001). However, these principles alone will no longer provide the answer to the on-going food security issues, which require a more holistic approach to both plant breeding (i.e., consideration of below-ground plant traits) and soil quality enhancement.

In less economically developed countries, the widespread use of non-renewable and increasingly expensive rock phosphate $(\mathrm{P})$ is now unfeasible at the required rates (Lynch 2007) and much of Africa's arable land is already sufficiently P-deficient to severely limit yields (Dery and Anderson 2007). In plants, $P$ is second in importance only to nitrogen $(\mathrm{N})$, forming a component of nucleic acids and phospholipids, assisting in enzyme activation and playing a role in carbon metabolism. However, in contrast to N, P mobility in soils is very low, with mass transport typically accounting for less than $5 \%$ of total root P uptake (Lambers et al. 2006). This difference is largely due to strong sorption of $\mathrm{P}$ to mineral surfaces (e.g., Fe/Al oxyhydroxides and $\mathrm{CaCO}_{3}$ ) resulting in low diffusion rates in soil (Shen et al. 2011). Studies measuring diffusion gradients of $P$ around roots commonly find that $\mathrm{P}$ concentration varies from a minimum at the root epidermis to the mean 'farfield' concentration over distances as short as $1 \mathrm{~mm}$ (Hinsinger et al. 2005; Lewis and Quirk 1967). Thus, the spatial distribution of $\mathrm{P}$ in the soil is highly relevant to plant acquisition in a way that is not nearly so distinct for more mobile plant resources such as water and $\mathrm{NO}_{3}{ }^{-}$.

Improvements in plant responses to low soil $\mathrm{P}$ availability must seek to exploit the wide range of existing plant traits which have been shown to enhance $\mathrm{P}$ acquisition from the rhizosphere (Herder et al. 2010). These could include alterations in root architecture (branching rates and angles, specific root length), the release of $\mathrm{P}$ mobilizing substances (e.g., organic acids and phosphatases), changes in mycorrhizal associations, and $\mathrm{P}$ transporter expression (Haling et al. 2013; Lambers et al. 2006; White et al. 2013). More work is also required to understand how roots adapt to heterogeneously distributed P (e.g., fertilisers) within the soil profile (Zoysa et al. 1997). In summary, strategies to maximize the capacity of crops to acquire $\mathrm{P}$ might best be achieved by an optimal synergy of soil P application protocols, specific root architecture traits and exudate-mediated solubilisation processes (Darrah et al. 2006; Hinsinger et al. 2005). The study of such parameters are often neglected in real soils, not due to their lack of importance, but as a consequence of the difficulty of visualizing the root-soil system in situ (Dittmer 1938; Lynch 1995). Moreover, the difficulty of measuring release rates and the composition of exudates in soil has led most studies to be performed in solution or gel culture that do not translate well to field conditions (Gregory and Hinsinger 1999; Heeraman et al. 1997; Pierret et al. 2005). Until recently, the majority of canonical methods for investigating roots in situ involve either root washing that results in a loss of root material and of spatially resolved data (Berntson and Woodward 1992; Dittmer 1938; Pagliai and De Nobili 1993; Sierra et al. 2003; Smucker et al. 1982) or rhizoboxes which constrain the observed root system to a 2D plane (Dinkelaker et al. 1993; Gibeaut et al. 1997; Schmidt et al. 2011; Wenzel et al. 2001). More recently, a number of studies have demonstrated the utility of X-ray-based, non-destructive tomographic imaging $(\mu \mathrm{CT})$ for visualising undisturbed plant root systems in real soils (Aylmore 1993; Dunbabin et al. 2013; Gregory and Hinsinger 1999; Gregory et al. 2003; Heeraman et al. 1997; Kaestner et al. 2006; Perret et al. 2007; Pierret et al. 2005; Stuppy et al. 2003). Increasingly, the imaging of plants at multiple time intervals is being incorporated into $\mu \mathrm{CT}$ studies, allowing longitudinal quantification of root trait development in relation to key soil parameters (Tracy et al. 2012). Of particular relevance to this study is the application of such a time-resolved (or '4D') $\mu \mathrm{CT}$ approach to the investigation of elevated rooting density within soil areas of elevated $\mathrm{P}$ concentration (Flavel et al. 2012). Previous research has noted that root proliferation can be locally up-regulated in the presence of $\mathrm{P}$ and $\mathrm{N}$ rich patches (Drew 1975; Hodge 2004), with $\mu C T$ imaging now offering a promising means by which to assess the behaviour of plant roots to different types of $\mathrm{P}$ resource in soil.

In response to the increased awareness that global $\mathrm{P}$ reserves are finite, there is increasing pressure to recover and re-utilize P from both solid and liquid waste streams (Cordell and White 2013). One potential solution for human and livestock wastewater is the precipitation of $\mathrm{P}$ 
as struvite which can then be recycled back to agricultural land. Struvite has been found to be an effective fertiliser with performance equivalent to traditional $\mathrm{P}$ fertilisers (Cabeza et al. 2011; Gell et al. 2011; Gonzalez-Ponce et al. 2009; Massey et al. 2009), although Ackerman et al. (2013) found that in an alkaline soil, struvite on its own was less effective than monoammonium phosphate.

In this study, 4D $\mu \mathrm{CT}$ imaging was applied to investigate the interaction of wheat roots with discrete granules of two contrasting P fertilisers: (1) monocalcium phosphate $\left(\mathrm{Ca}\left(\mathrm{H}_{2} \mathrm{PO}_{4}\right)_{2} \cdot \mathrm{H}_{2} \mathrm{O}\right.$; Triple Superphosphate; TSP), a traditional $\mathrm{P}$ fertiliser with high water solubility, and (2) struvite $\left(\mathrm{MgNH}_{4} \mathrm{PO}_{4} * 6 \mathrm{H}_{2} \mathrm{O}\right)$ which has a lower water solubility. Our aims were to compare the solubilisation rates of the different fertilisers and to correlate this solubilisation behaviour with root development around discrete granules. The ability to quantify and compare these parameters in situ under realistic soil conditions will open up opportunities to screen different genotypes and fertiliser delivery strategies, particularly by matching dissolution rates to plant lifecycle events.

\section{Materials and methods}

\section{Plant growth conditions}

Individual spring wheat plants (Triticum aestivum L. cv Granary; KWS UK Ltd., Thriplow Hertfordshire, UK) were grown in individual PVC columns of $110 \mathrm{~mm}$ diameter and $500 \mathrm{~mm}$ height. The column dimensions were chosen to optimize $\mu \mathrm{CT}$ image-quality while still allowing plants to grow to maturity. The soil used to fill the columns constituted a $\mathrm{P}$-deficient $($ Olsen $\mathrm{P}=$ $\left.12.6 \mathrm{mg}^{-1}\right)$, sandy loam textured Eutric Cambisol (0$15 \mathrm{~cm}$ depth, Ahp horizon) collected from a freely draining grassland located in Abergwyngregyn, UK $\left(53^{\circ} 14^{\prime} \mathrm{N}, 4^{\circ} 01^{\prime} \mathrm{W}\right)$. The Olsen P level corresponds to an Index-I fertility soil for which it is recommended that $40 \mathrm{~kg} \mathrm{P} \mathrm{ha}{ }^{-1}$ be added to achieve maximal wheat yields (DEFRA 2010). After collection, the soil was sieved to pass $5 \mathrm{~mm}$ (initial gravimetric soil water content was 12.5). Each column was sown centrally with three seeds, but was subsequently thinned to retain the single most vigorous seedling ( $5 \mathrm{~d}$ after sowing). Two contrasting $\mathrm{P}$ fertilisers were used: (1) triple superphosphate (TSP; $\left.\mathrm{Ca}\left(\mathrm{H}_{2} \mathrm{PO}_{4}\right)_{2} \mathrm{H}_{2} \mathrm{O}\right)$ derived from rock phosphate, and (2) Crystal Green ${ }^{\circledR}\left(\mathrm{CG} ; \mathrm{MgNH}_{4} \mathrm{PO}_{4} 6 \mathrm{H}_{2} \mathrm{O}\right)$, a slow release struvite fertiliser produced from wastewater (Ostara Nutrient Recovery Technologies Inc., Vancouver, BC) (Fig. 1). The two P sources were used in three treatments as follows: Treatment 1 , TSP added at a rate equivalent to $80 \mathrm{~kg} \mathrm{P}_{2} \mathrm{O}_{5} \mathrm{ha}^{-1}$; Treatment 2, struvite $\mathrm{CG}$ added at a rate of $80 \mathrm{~kg} \mathrm{P}_{2} \mathrm{O}_{5} \mathrm{ha}^{-1}$; Treatment 3, a mixture of TSP and CG each added at a rate of $40 \mathrm{~kg} \mathrm{P}_{2} \mathrm{O}_{5} \mathrm{ha}^{-1}$. Fertiliser granules were placed $50 \mathrm{~mm}$ from the soil surface and $25 \mathrm{~mm}$ from the centre of the pot. Each treatment was replicated three times. The soil was supplemented with micronutrients by the weekly addition of $25 \mathrm{ml}$ of P-free full strength Hoagland's solution (Hoagland and Arnon 1950). N was applied to each column as $\mathrm{NH}_{4} \mathrm{NO}_{3}$ at a rate equivalent to $62 \mathrm{~kg} \mathrm{~N} \mathrm{ha}^{-1}$ once following shoot emergence and once during the reproductive stem-extension stage following tillering, while $\mathrm{K}$ was applied once as $\mathrm{KCl}$ following shoot emergence at a rate equivalent to $50 \mathrm{~kg} \mathrm{~K} \mathrm{ha}{ }^{-1}$. The planted columns were placed in a glasshouse with $16 / 8 \mathrm{~h}$ day/night cycle and air temperature of $20^{\circ} \mathrm{C}$. The columns were watered by capillary
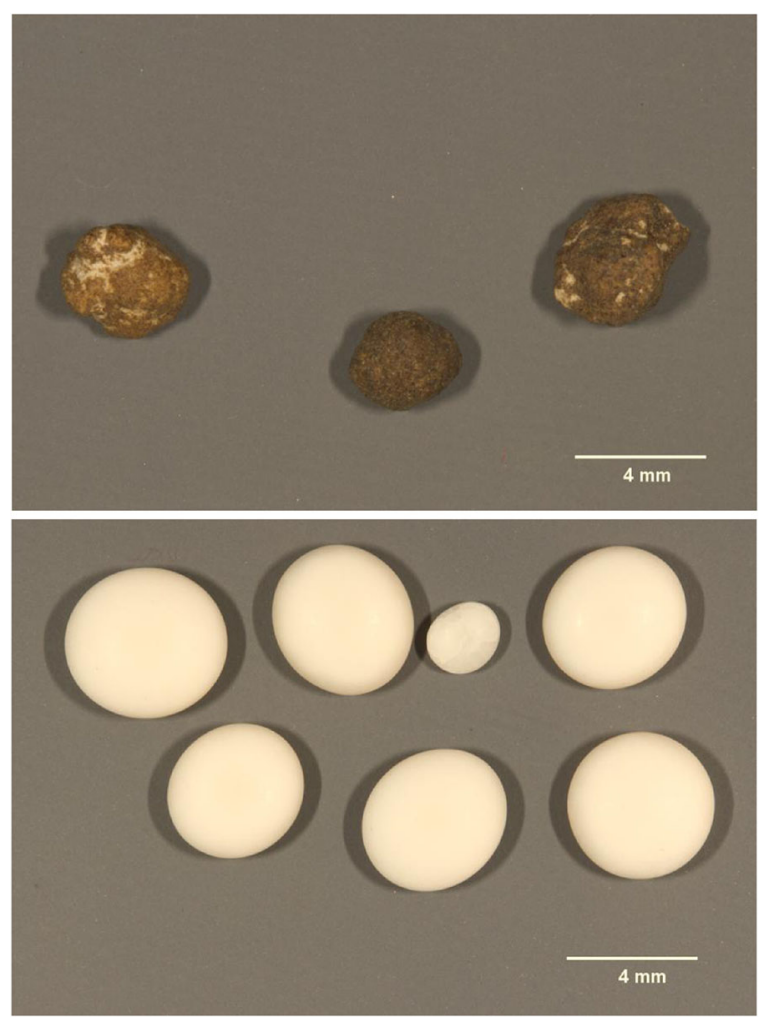

Fig. 1 Photographs showing the two fertiliser types used in the experiments. Bottom: slow-release struvite (Crystal Green ${ }^{\circledR}$; $\left.\mathrm{MgNH}_{4} \mathrm{PO}_{4} \cdot 6 \mathrm{H}_{2} \mathrm{O}\right)$; Top: Triple superphosphate $\left(\mathrm{Ca}\left(\mathrm{H}_{2} \mathrm{PO}_{4}\right)_{2} \cdot \mathrm{H}_{2} \mathrm{O}\right)$ 
action from water-filled trays placed underneath the columns with a water depth of $50 \mathrm{~mm}$. This was supplemented by watering the columns from the top three times a week with $500 \mathrm{ml}$ of distilled water. All watering ceased 2 days prior to $\mu \mathrm{CT}$ imaging to improve image quality and reduce the scan time by lowering the mean cross-sectional X-ray absorption of the sample. There were three replicate columns for each treatment.

Time lapse X-ray imaging

All the columns were imaged using a custom-design micro-focus Nikon 'hutch' $\mu \mathrm{CT}$ scanner (Nikon Metrology Europe, Leuven, Belgium) at 2, 4, 6, 8, 10 and 14 weeks post-planting. The pots were not imaged in the early stages of growth (i.e., prior to week 2) as the roots would have been too far away from the P sources for any meaningful analysis. Data were acquired using an accelerating potential of $150 \mathrm{kV}$ and tube current of $15.15 \mathrm{~W}$. A total of 3142 equiangular projections were acquired (per column) through $360^{\circ}$ using a flat panel detector with 2048 x 2048 isometric elements.

Average scan time was 56 min column ${ }^{-1}$. This allowed all columns to be scanned in under $9 \mathrm{~h}$. A proprietary filtered back-projection algorithm implemented in CTPro 3D, (Nikon Metrology, Tring, UK) was used to reconstruct the projections into $3 \mathrm{D}$ volume datasets with an isometric voxel (analogous to a pixel with volume) resolution of $60 \mu \mathrm{m}$. Each resulting dataset comprised a stack of 2048 images, each with an image size of 2048 x 2048 voxels.

\section{D image analysis}

Extraction of roots from three dimensional densitometric data remains challenging under real soil conditions (Mooney et al. 2011; Tracy et al. 2012). This is especially true for plants such as wheat because of the relatively fine roots (max. diameter of up to $200 \mu \mathrm{m}$; Watt et al. (2008)). Furthermore, the material density range of plant roots is similar to those of the pore-water and organic matter fractions that constitute the surrounding soil (Kaestner et al. 2006). Consequently, automated segmentation using standard computer vision algorithms is difficult to apply and does not yield reliable results (Coleman and Colbert 2007). Though dedicated software tools for automated root segmentation are becoming available (e.g., RooTrack; Mairhofer et al. (2012); RootViz3D, www.rootviz3d.org), this trial and those of other researchers in the field (e.g., Flavel et al. (2014)) indicate that further development is required to overcome limitations imposed by the heterogeneity of real soils and intermediate imaging resolutions. As a result, manual segmentation was considered the most suitable root classification method in this case. A graphical tablet with an integrated high resolution display (Cintiq 24, Wacom Technology Corp., Vancouver, WA) was used in conjunction with voxel labelling (Avizo Fire v8; FEI Co., Hillsboro, OR) to manually select the individual voxels associated with a root in each slice of the stack. A 3D interpolation algorithm within Avizo Fire was used to significantly speed up feature extraction. With this method, measured volume can be unreliable due to the linear interpolation used to form a continuous link between two manually selected root cross-sections. Therefore, root quantification was carried out using three dimensional root lengths determined using the Length3D plugin within Avizo Fire v8.

Root segmentation was performed at two scales. At the large scale, all visible roots down to $\sim 60 \mathrm{~mm}$ below the soil surface were segmented. This cut-off was chosen to exclude root sections that had become column-bound and grown down the soil-column interface. This large scale segmentation was only performed for one 50:50 treatment replicate. Small scale root segmentation was performed on cubic sub-volumes $\left(10 \mathrm{~mm}^{3}\right)$ around each fertiliser granule (Fig. 2) for all fertiliser treatments and replicates.

A semi-automated protocol was developed for segmentation of the struvite granules. This involved a systematic use of median noise filtration, edge enhancement (Canny edge detection) and region growing from manually determined seed points. The volume of the segmented granule was determined by counting the number of voxels that were contained in the feature and multiplying it by the volume occupied by a single voxel $(60 \times 60 \times 60 \mu \mathrm{m})$. Reliable volume measurement of the TSP granules was not possible since they dispersed into small fragments during dissolution. Consequently, volumetric analysis of the TSP granules was not performed (see Fig. 6 for illustration).

\section{Results}

Root growth over time

Figure 2 shows an example of the 3D root system architecture determined by $\mu \mathrm{CT}$ in the 50:50 TSP:CG 


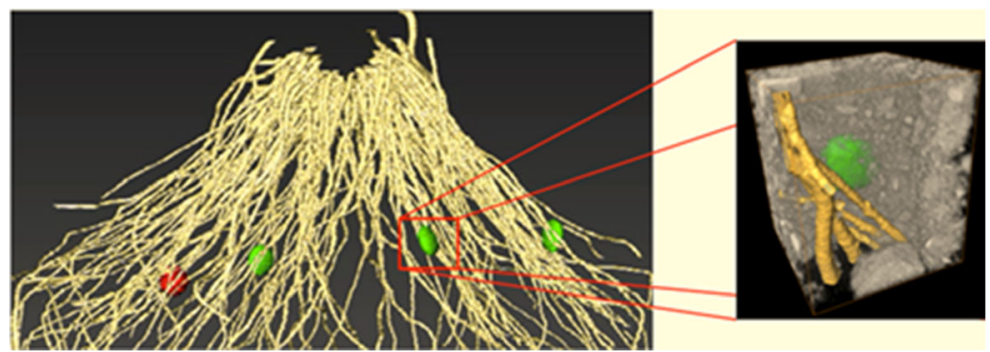

Fig. 2 3D rendering of $\mu \mathrm{CT}$ imaging data of the root system for a representative 50:50 TSP:struvite treatment. The green areas are struvite granules and the red area is an approximate shadow of one TSP granule. The close up rendering illustrates the $10 \mathrm{~mm}^{3} \mathrm{sub}-$ volume in which the small scale measurements of root length and fertiliser volume change were conducted. The column diameter was $110 \mathrm{~mm}$

for the entire 14 week period (Fig. 6). Table 1 shows the mean volume loss associated with individual struvite granules for the two struvite treatments (50:50 TSP:struvite and $100 \%$ struvite) at the end of the 14 week experiment. On average, struvite granules in the 50:50 TSP:struvite treatment lost $40 \%$ more volume compared to those in the struvite only treatment. The mean volume changes of struvite granules in the 50:50 and struvite-only treatments were significantly different $(P=0.02)$.

Changes in struvite granule volume and associated local root lengths over time are shown in Fig. 7. The average [linear] rate of dissolution of struvite was calculated to be $0.75 \mathrm{~mm}^{3} \mathrm{w}^{-1}$ under the given conditions. During the first 6 weeks, the volumes of the struvite granules did not change appreciably in volume $(P>0.05)$, with no root growth being observed within the small scale regions of interest. Over time and as roots began to ingress into the $10 \mathrm{~mm}^{3}$ regions of interest around the granules, a concurrent loss in granule volume was observed. Figure 8 shows the significant linear correlation between average struvite granule volume loss versus the average root length in the region of interest $\left(R^{2}=0.9065\right)$.

The TSP granules were difficult to identify reliably due to their similarity in texture to the surrounding soil (Fig. 6). In contrast the struvite granules could be seen
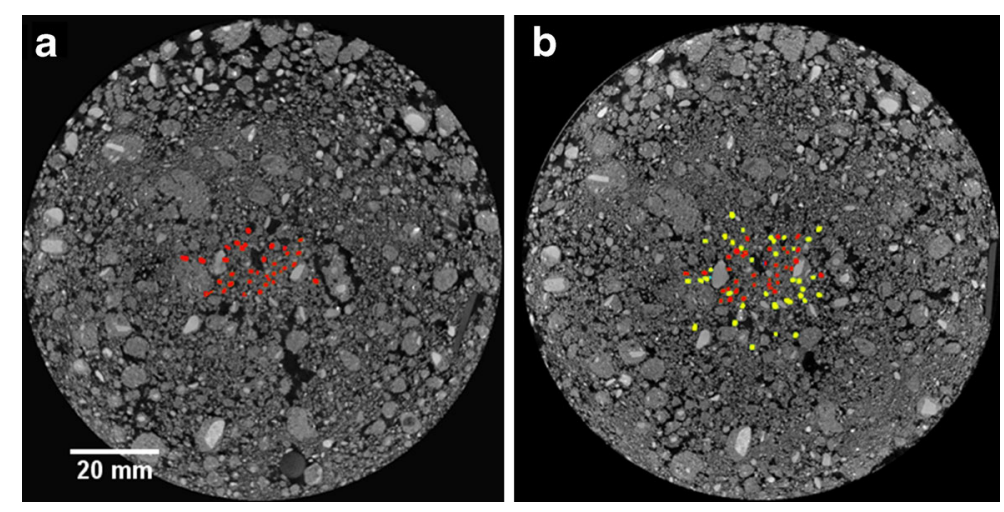

Fig. 3 Horizontal $\mu \mathrm{CT}$ slice taken from $3 \mathrm{D}$ reconstructed dataset visualising the internal structure of the soil and the distribution of roots at (a) week 8 , and (b) week 10. The areas highlighted in red are roots seen at the end of week $8(n=33)$ and the yellow highlighted areas are the additional roots seen at the end of week $10(n=35)$ 
Fig. 4 3D rendering from the time lapse $\mu \mathrm{CT}$ imaging showing the change over time of the root system for the top $60 \mathrm{~mm}$ of the soil column at: (a) week 4, (b) week 8 , and (c) week 14 in a 50:50 TSP:struvite treatment. The column diameter is $110 \mathrm{~mm}$

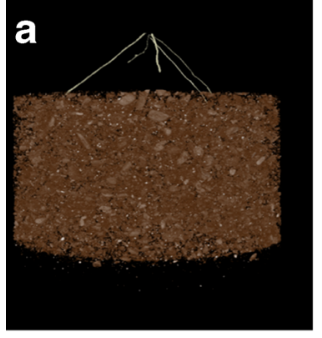

Week-4

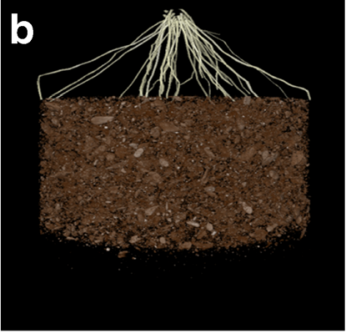

Week-8

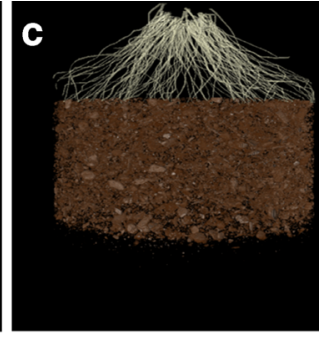

Week-12

\section{Discussion}

In this study we demonstrate an innovative application of $\mu \mathrm{CT}$ imaging to examine the interaction of fertiliser granules and roots over a 14 week period, using large live plants in a real agricultural soil. The protocols developed for in vivo time resolved imaging show promise for future studies.

Results from the large scale root segmentation exercise show that the rate of root system growth for wheat plants occurred in three distinct stages. Initially, the rate of new root production and extension of existing roots is slow. Once the roots acquire access to the nutrient point sources (i.e., fertiliser granules) through sufficient proximity, the rate of root length increase rises rapidly. As the plants

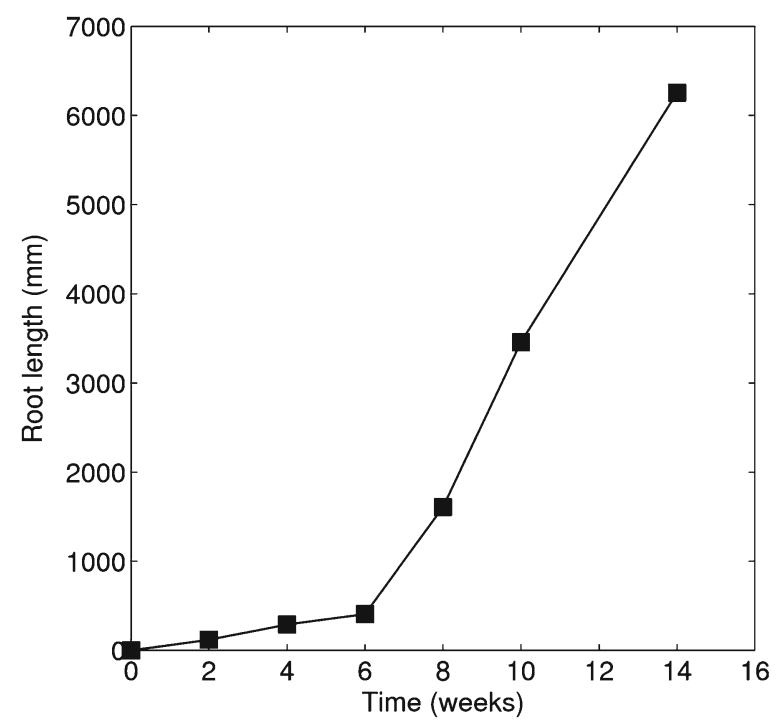

Fig. 5 Change in root length over time in a representative soil column from the 50:50 TSP:struvite treatment. Large scale root length quantification was done for the top $60 \mathrm{~mm}$ of the soil profile at weeks $2,4,6,8,10$, and 14 entered the grain-filling stage, only a marginal reduction in the rate of root length increase was observed.

Analysis of the relationship between fertiliser granule volume and the local root length density shows that struvite-based fertiliser tends to have a very slow rate of dissolution in slightly acidic soil ( $\mathrm{pH}$ 5.9) when proximal root growth (within $5 \mathrm{~mm}$ of granules) is absent. When roots begin to enter the $10 \times 10 \times 10 \mathrm{~mm}^{3}$ sub-volumes of interest (centred on each granule), dissolution of the granules begins to occur more rapidly. Between weeks 6 and 8 , the struvite granules (in all three 50:50 TSP:struvite columns) lost $18 \%$ of their volume. At the same time, root length in the $10 \mathrm{x} 10 \mathrm{x}$ $10 \mathrm{~mm}^{3}$ sub-volume surrounding the granule also increased. Over time, root length in these cuboids continues to increase, however, the rate of dissolution of the fertiliser granules slows. As root tips grow away from the fertiliser granules, there is likely to be a reduction in root exudation (e.g., organic acids), which is predominantly focused around the tips and known to promote struvite dissolution (data not presented; Hinsinger et al. (2003)). There is a fairly strong relationship between root length and granule volume loss $\left(R^{2}=0.91\right)$ as shown in Fig. 8. We hypothesise that the reduction in struvite granule volume in the presence of roots is due to plant-mediated chemical, hydrological and/or mechanical processes. The scans and analysis provide an empirical link between dissolution rate and root proximity, but do not offer mechanistic insight as to the processes involved in the dissolution of the struvite granules. Of the various mechanisms that might be implicated in struvite granule dissolution, we posit three: (1) The influence of root exudates (particularly the organic acids citrate, malate and oxalate) can lead to regions of low $\mathrm{pH}$ in the near-root zone, in which struvite solubility is increased. The extent of this region in soil has been determined by various workers as $<3 \mathrm{~mm}$ (Zoysa et al. 1997). (2) The presence of an active P-sink at root 
Fig. 6 Horizontal $\mu \mathrm{CT}$ slice taken from $3 \mathrm{D}$ reconstructed dataset visualising the change in shape and internal texture of a TSP granule at week 4 (a) and at week 14 (b) and of a struvite granule at week 4 (c) and week 14 (d). Red circles show our approximate estimate of TSP granule location while green circles show a struvite granule

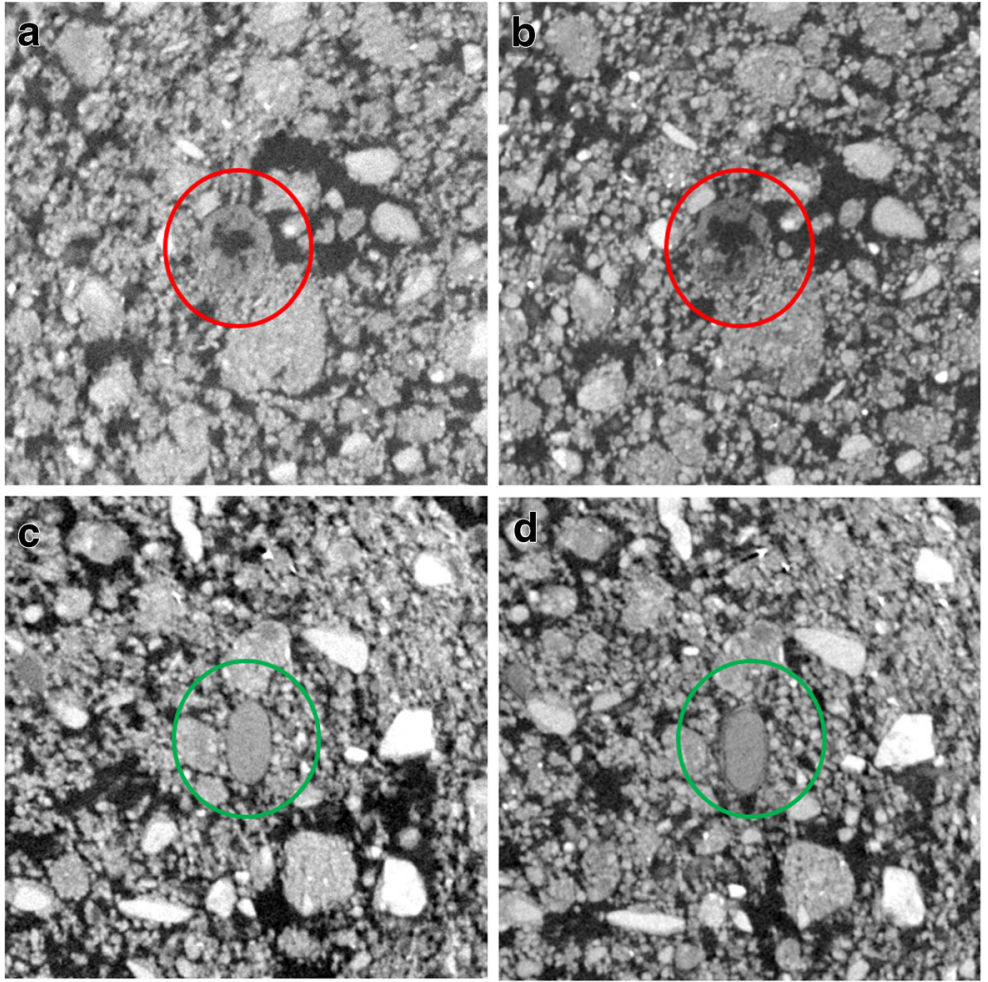

epidermal plasma membranes creates strong nutrient gradients in the soil due to the low effective diffusion coefficient of $\mathrm{P}$, decreasing the $\mathrm{P}$ concentration in the soil solution in the near-root zone. The soil-solution concentration is then restored to equilibrium with $\mathrm{P}$ from the struvite granule. (3) Fine roots, root hairs and fungal hyphae could potentially be in direct contact with granules, influencing release of $\mathrm{P}$. However, fine roots

Table 1 Mean volume loss from either triple superphosphate $(T S P)$ or struvite $\left(\right.$ Crystal Green $\left.{ }^{\circledR}\right)$ fertilizer granules after 14 weeks and the associated amount of root proliferation around the granule (measured after 14 weeks in a $10 \mathrm{~mm}^{3}$ sub-volume centered around the granule). The 50:50 treatment included equal amounts (diameter $<100 \mu \mathrm{m}$ ) and root hairs were not visualized in this study at the scan resolution used.

A $t$-test comparing the mean volume change of struvite granules over 14 weeks showed significantly greater volume loss in the 50:50 TSP:struvite treatment (Table 1). We hypothesize that this might be related to having a complimentary $\mathrm{P}$ source that is more water soluble and therefore more readily available during early

of TSP and struvite with data presented separately for both granule types. Values represent means \pm SEM. $T$-test of average root length pairs marked with ${ }^{*},{ }^{\square}$ and were statistically different, i.e., $P<0.05$. Two other pairs were not statistically different (i.e., $P>0.05)$

\begin{tabular}{lll}
\hline & $\begin{array}{l}\text { Rate of granule volume change } \\
\left(\mathrm{mm}^{3} \text { week }^{-1}\right)^{\mathrm{a}}\end{array}$ & $\begin{array}{l}\text { Average root length near granule } \\
\text { after 14 weeks (mm) }\end{array}$ \\
\hline Struvite & $0.38 \pm 0.02$ & $7.27 \pm 0.22^{*} \square$ \\
Struvite (50:50 treatment) & $0.54 \pm 0.03$ & $7.43 \pm 0.37^{*}$ \\
TSP & $\mathrm{ND}^{\mathrm{b}}$ & $7.43 \pm 0.60$ \\
TSP (50:50 treatment) & $\mathrm{ND}$ & $9.15 \pm 0.64^{\square}$ \\
\hline
\end{tabular}

\footnotetext{
${ }^{\text {a }}$ Calculated by measuring the change in granule volume $(n>9)$ between weeks 2 and 14

${ }^{\mathrm{b}} \mathrm{ND}$, not determined. The rate of TSP dissolution could not be calculated due to rapid physical deterioration of the granule during the dissolution process
} 


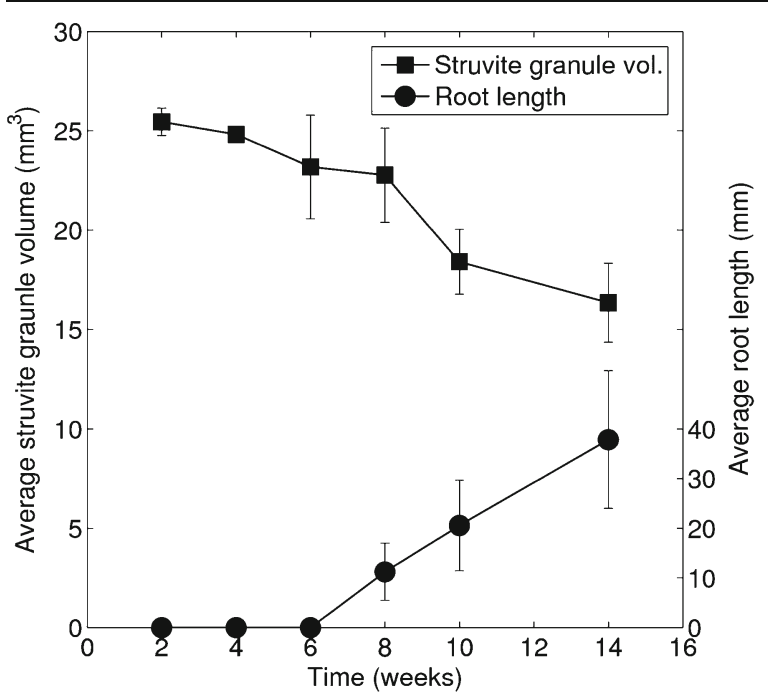

Fig. 7 Volume change of struvite granules and cumulative root length in $10 \mathrm{~mm}^{3}$ sub-volumes over a 14 week period. Values are the mean \pm SD of all regions of interest with struvite granules in the 50:50 TSP:struvite treatment columns

plant growth; having a source of more readily available $\mathrm{P}$ may have boosted early root growth that in turn resulted in greater dissolution of the struvite granules. At 14 weeks, the volumes of interest around TSP granules in the 50:50 columns had the greatest average root length, which could be an indicator to support this

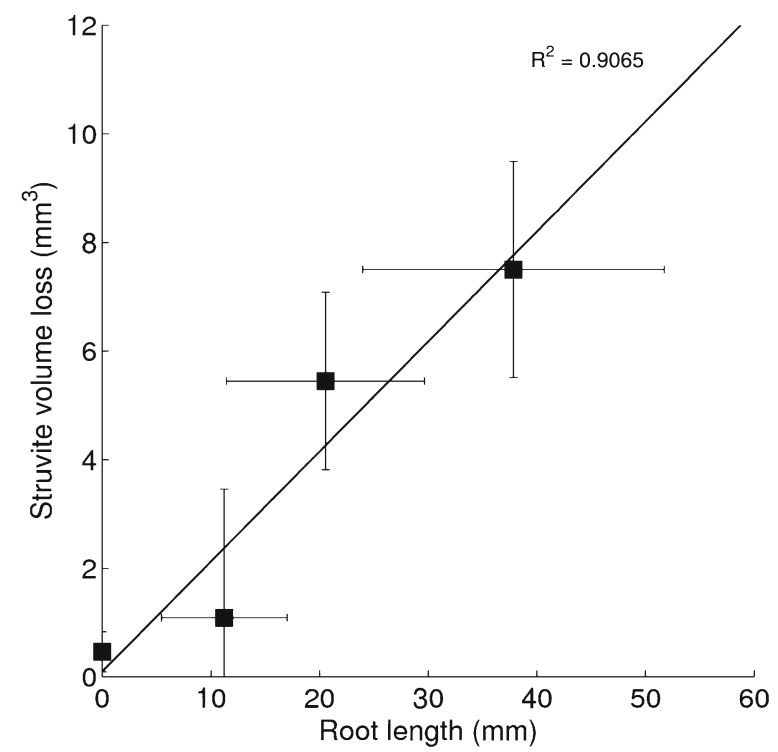

Fig. 8 Correlation between root length and granule volume loss measured over 14 weeks for the 50:50 TSP:struvite treatment columns. Values represent mean $\pm \mathrm{SD}$ while the solid line indicates a linear regression fitted to the experimental data hypothesis. Pot conditions represent a necessary abstraction from the unconstrained field state, however, in this study the placement of granules avoided any simple influence on length density from the chamber walls. Primary roots interacting with the chamber walls did so beneath the level of the granules, such that further interaction with the granules was not possible. As to possible systemic effects on branching and secondary root length resulting from plant sensing of the constrained condition, this study did not consider hormone signalling and thus such effects cannot be determined.

The spatial resolution achieved in this study $(60 \mu \mathrm{m})$ is on par with similar contemporary studies (e.g., Flavel et al. 2014). However, we did not detect any localised increase in branching density. Imaging approaches to study plants are necessarily multiscale endeavours, and whilst imaging smaller-scale samples might shed light on finer-scale root architecture and complement the findings of this study, such systems also necessitate a greater and undesirable constraint of plant roots.

$\mu \mathrm{CT}$ imaging was established as an effective method for evaluating granule volume loss, representing a proxy for traditional assessments of nutrient release. This could be a useful tool since the solubility characteristics of struvite (having very low water solubility, while still being fully soluble in neutral ammonium citrate) do not lend themselves to traditional methods of generating fertiliser release curves (Braithwaite 1987) and as shown in the study, the interaction with a growing plant is an important component of the release. Although not within the scope of the current study, laboratory measurements of Olsen $\mathrm{P}$ and organic acids at discrete depth intervals could be complementary to similar studies undertaken in the future.

Overall, this study demonstrates that the granular struvite fertiliser employed in this study dissolves slowly in acidic soil in the absence of roots, revealing via in situ methods that the mechanism(s) causing struvite dissolution (and thus $\mathrm{P}$ release) are correlated with close proximity to plant roots. These findings clearly provide a motivation to optimise the design and distribution of struvite fertiliser granules in soil. Future studies might particularly focus on determining optimal placement and granule size such that granule dissolution is matched to the lifecycle of the plant. 
Acknowledgments SA was funded by EPSRC Knowledge Transfer Partnership with Ostara Nutrient Recovery Technologies Inc. TR was funded by BBSRC BB/I024283/1, BB/J000868/1, BB/J011460/1 and NERC NE/L000237/1.

\section{References}

Ackerman JN, Zvomuya F, Cicek N, Flaten D (2013) Evaluation of manure-derived struvite as a phosphorus source for canola. Can J Plant Sci 93:419-424

Aylmore AG (1993) Use of computer-assisted tomography in studying water movement around plant roots. Adv Agron 49:1-54

Berntson GM, Woodward FI (1992) The root system architecture and development of Senecio vulgaris in elevated $\mathrm{CO} 2$ and drought. Funct Ecol 6:324-333

Braithwaite AC (1987) The use of chemical solubility tests in comparing phosphate fertilizers. Pert Res 12:185-192

Cabeza R, Steingrobe B, Romer W, Claassen N (2011) Effectiveness of recycled $\mathrm{P}$ products as $\mathrm{P}$ fertilizers, as evaluated in pot experiments. Nutr Cycl Agroecosyst 91:173-184

Coleman MN, Colbert MW (2007) Technical note: CT thresholding protocols for taking measurements on threedimensional models. Am J Phys Anthropol 133:723-725

Cordell D, White S (2013) Sustainable phosphorus measures: strategies and technologies for achieving phosphorus security. Agronomy 3:86-116

Darrah PR, Jones DL, Kirk GJD, Roose T (2006) Modelling the rhizosphere: a review of methods for 'upscaling' to the whole-plant scale. Eur J Soil Sci 57:13-25

DEFRA (2010) Fertiliser Manual RB209, 8th edn. Department for Environment, Food and Rural Affairs, TSO, Norwich

Dery P, Anderson B (2007) Peak phosphorus. Energy Bull 13

Dinkelaker B, Hahn G, Römheld V, Wolf GA, Marschner H (1993) Non-destructive methods for demonstrating chemical changes in the rhizosphere I. Description of methods. Plant Soil 155:67-70

Dittmer HJ (1938) A quantitave study of the subterranean members of three field grasses. Am J Bot 25:654-657

Drew MC (1975) Comparison of the effects of a localised supply of phosphate, nitrate, ammonium and potassium on the growth of the seminal root system, and the shoot, in barley. New Phytol 75:479-490

Dunbabin VM, Postma JA, Schnepf A, Pagès L, Javaux M, Wu L, Leitner D, Chen YL, Rengel Z, Diggle AJ (2013) Modelling root-soil interactions using three-dimensional models of root growth, architecture and function. Plant Soil 372:1-32

Flavel RJ, Guppy CN, Tighe M, Watt M, McNeill A, Young IM (2012) Non-destructive quantification of cereal roots in soil using high-resolution X-ray tomography. J Exp Bot 63: 2503-2511

Flavel RJ, Guppy CN, Tighe MK, Watt M, Young IM (2014) Quantifying the response of wheat (Triticum aestivum L) root system architecture to phosphorus in an Oxisol. Plant Soil 385:303-310

Gell K, de Ruijter FJ, Kuntke P, de Graaff M, Smit A (2011) Safety and effectiveness of struvite from black water and urine as a phosphorus fertilizer. J Agric Sci 3:67

Gibeaut DM, Hulett J, Cramer GR, Seemann JR (1997) Maximal biomass of arabidopsis thaliana using a simple, low- maintenance hydroponic method and favourable enfironmental conditions. Plant Physiol 115:317-319

Godfray HCJ, Beddington JR, Crute IR, Haddad L, Lawrence D, Muir JF, Pretty J, Robinson S, Thomas SM, Toulmin C (2010) Food security: the challenge of feeding 9 billion people. Science 327:812-818

Gonzalez-Ponce R, Lopez-de-Sa EG, Plaza C (2009) Lettuce response to phosphorus fertilization with struvite recovered from municipal wastewater. HortSci 44:426-430

Gregory PJ, Hinsinger P (1999) New approaches to studying chemical and physical changes in the rhizosphere: an overview. Plant Soil 211:1-9

Gregory PJ, Hutchison DJ, Read DB, Jenneson PM, Gilboy WB, Morton EJ (2003) Non-invasive imaging of roots with highresolution X-ray micro-tomography. Plant Soil 255:351-359

Haling RE, Brown LK, Bengough AG, Young IM, Hallett PD, White PJ, George TS (2013) Root hairs improve root penetration, root-soil contact, and phosphorus acquisition in soils of different strength. J Exp Bot 64:3711-3721

Heeraman DA, Hopmans JW, Clausnitzer V (1997) Three dimensional imaging of plant roots in situ with $\mathrm{x}$-ray computed tomography. Plant Soil 189:167-179

Herder GD, Van Isterdael G, Beeckman T, De Smet I (2010) The roots of a new green revolution. Trends Plant Sci 15:600-607

Hinsinger P, Plassard C, Tang C, Jaillard B (2003) Origins of rootmediated $\mathrm{pH}$ changes in the rhizosphere and their responses to environmental constraints: a review. Plant Soil 248:43-59

Hinsinger P, Gobran GR, Gregory PJ, Wenzel WW (2005) Rhizosphere geometry and heterogeneity arising from rootmediated physical and chemical processes. New Phytol 168: 293-303

Hoagland DR, Arnon DI (1950) The water-culture method for growing plants without soil. Circ Calif Agric Exp Stn 347:32

Hodge A (2004) The plastic plant: root responses to heterogeneous supplies of nutrients. New Phytol 162:9-24

Kaestner A, Scneebli M, Graf F (2006) Visualising threedimensional root networks using computed tomography. Geoderma 136:459-469

Khush GS (2001) Green revolution: the way forward. Nat Rev Genet 2:815-822

Lambers H, Shane MW, Cramer MD, Pearce SJ, Veneklass EJ (2006) Root structure and functioning for efficient acquisition of phosphorus: matching morphological and physiological traits. Ann Bot 98:693-713

Lewis DG, Quirk JP (1967) Phosphate diffusion in soil and uptake by plants. Plant Soil 26:99-118

Lynch J (1995) Root architecture and plant productivity. Plant Physiol 109:7-13

Lynch JP (2007) Turner review no. 14. Roots of the second green revolution. Aust J Bot 55:493-512

Mairhofer S, Zappala S, Tracy SR, Sturrock C, Bennett M, Mooney SJ, Pridmore T (2012) RooTrak: automated recovery of three-dimensional plant root architecture in soil from $\mathrm{x}$-ray microcomputed tomography images using visual tracking. Plant Physiol 158:561-569

Massey MS, Davis JG, Ippolito JA, Sheffield RE (2009) Effectiveness of recovered magnesium phosphates as fertilizers in neutral and slightly alkaline soils. Agron J 101:323-329

Mooney SJ, Pridmore TP, Helliwell J, Bennett MJ (2011) Developing $\mathrm{X}$-ray computed tomography to non-invasively image 3-D root systems architecture in soil. Plant Soil 352:1-22 
Pagliai M, De Nobili M (1993) Relationships between soil porosity, root development and soil enzyme activity in cultivated soils. Geoderma 56:243-256

Perret JS, Al-Belushi ME, Deadman M (2007) Non-destructive visualisation and quantification of roots using computed tomography. Soil Biol Biochem 39:391-399

Pierret A, Moran CJ, Doussan C (2005) Conventional detection methodology is limiting our ability to understand the roles and functions of fine roots. New Phytol 166:967-980

Schmidt H, Eickhorst T, Tippkötter R (2011) Monitoring of root growth and redox conditions in paddy soil rhizotrons by redox electrodes and image analysis. Plant Soil 341:221-232

Shen J, Yuan L, Zhang J, Li H, Bai Z, Chen X, Zhang W, Zhang F (2011) Phosphorus dynamics: from soil to plant. Plant Physiol 156:997-1005

Sierra CA, Del Valle JI, Orrego SA (2003) Accounting for fine root mass sample losses in the washing process: a case study from a tropical montaine forest of Colombia. J Trop Ecol 19: 599-601

Smucker AJM, McBurney SL, Strivastava AK (1982) Quantitative separation of roots from compacted soil profiles by the hydropneumatic elutriation system. Agron J 7:500-503
Stuppy W, Maisano JA, Colbert MW, Rudall PJ, Rowe TB (2003) Three-dimensional analysis of plant structure using highresolution X-ray computed tomography. Trends Plant Sci 8: 2-6

Tracy S, Black C, Roberts J, McNeill A, Davidson R, Tester M, Samec M, Korošak D, Sturrock C, Mooney S (2012) Quantifying the effect of soil compaction on three varieties of wheat using X-ray Micro Computed Tomography (CT). Plant Soil 353:195-208

Watt M, Magee LJ, McCully ME (2008) Types, structure and potential for axial water flow in the deepest roots of fieldgrown cereals. New Phytol 178:135-146

Wenzel WW, Wieshammer G, Fitz WJ, Puschenreiter M (2001) Novel rhizobox design to assess rhizosphere characteristics at high spatial resolution. Plant Soil 237:37-45

White PJ, George TS, Gregory PJ, Bengough AG, Hallett PD, McKenzie BM (2013) Matching roots to their environment. Ann Bot 112:207-222

Zoysa AKN, Loganathan P, Hedley MJ (1997) A technique for studying rhizosphere processes in tree crops: soil phosphorus depletion around camellia (Camellia japonica L.) roots. Plant Soil 190:253-265 